\title{
A segurança jurídica dos atos administrativos e a objetivação das demandas refletidas no art. 30 da nova LINDB*
}

\section{The legal certainty of administrative acts and the objectivation of demands reflected in the Article 30 of the new LINDB}

\author{
Henrique Ribeiro Cardoso** \\ Davi Barretto Dória***
}

* Artigo recebido em 20 de março de 2020 e aprovado em 17 de junho de 2020. DOI: http:// dx.doi.org/10.12660/rda.v279.2020.82960.

** Universidade Tiradentes e Escola Superior do Ministério Público de Sergipe, Aracaju, SE, Brasil. E-mail: henrique@mpse.mp.br

Doutor em direito, estado e cidadania (UGF/Rio), com pós-doutorado em democracia e direitos humanos (IGC - Universidade de Coimbra) e pós-doutorado em direitos humanos e desenvolvimento (PPGCJ/UFPB); mestre em direito, estado e cidadania (UGF/Rio); especialista em direito constitucional processual (FAPESE/UFS); graduado em direito pela Universidade Estadual de Santa Cruz (UESC/Bahia); professor do Programa de Pós-graduação da Universidade Federal de Sergipe (Mestrado/PRODIR/UFS); professor de Programa de Pós-graduação da Universidade Tiradentes (Doutorado/Mestrado/PPGD/UNIT); professor da Escola Superior do Ministério Público de Sergipe (ESMP/SE); membro da Academia Sergipana de Letras Jurídicas (ASLJ/SE) e líder do Grupo de Pesquisa Constitucionalismo, Cidadania e Concretização de Políticas Públicas. Promotor de justiça em Sergipe desde agosto de 1997, titular da Primeira Curadoria da Fazenda Pública de Aracaju desde 2002.

*** Universidade Federal de Sergipe, São Cristóvão, SE, Brasil. E-mail: davidoria@gmail.com Procurador do estado de Sergipe. Advogado. Mestrando em direito pela Universidade Federal de Sergipe (UFS). Bacharel em direito pela Universidade Federal de Sergipe (UFS). Especialista em direito tributário pela Pontifícia Universidade Católica de Minas Gerais PUC/MG. Especialista em direito constitucional. Foi procurador do município de Curitiba, lotado na procuradoria fiscal. É membro da comissão de advocacia estatal da OAB/SE. 


\section{RESUMO}

A trajetória da legislação brasileira demonstra a intenção do legislador em garantir, na ordem prática, o princípio da segurança jurídica. O problema analisado neste artigo parte da constatação de que esse princípio positivado na Constituição Federal não estava devidamente disciplinado e regulamentado na seara administrativa. Como hipótese, busca-se examinar as recentes inovações na LINDB que demonstram a necessidade de consagração do mencionado princípio. Atento à nova conformação da administração pública, o legislador acrescentou o art. 30 à LINDB, com a finalidade de assegurar uma maior observância da segurança jurídica na aplicação da norma. O objetivo deste artigo é elucidar o conceito de segurança jurídica que passa a ter densidade normativa e conteúdo próprios nesta inovação legislativa.

\section{PALAVRAS-CHAVE}

LINDB - objetivação - consequencialismo - segurança jurídica

\section{ABSTRACT}

The trajectory of Brazilian legislation demonstrates the legislator's intention to guarantee, in practical order, the principle of legal certainty. The problem analyzed in this article is based on the observation that this principle, as established in the Federal Constitution, was not properly disciplined and regulated in the administrative field. As a hypothesis, this paper seeks to examine the recent innovations in LINDB that demonstrate the need to enshrine the aforementioned principle. Attentive to the new conformation of the public administration, the legislator added art. 30 to LINDB, in order to ensure greater compliance with legal certainty in the application of the standard. The purpose of this article is to elucidate the concept of legal certainty that has its own regulatory density and content.

\section{KEYWORDS}

LINDB - objectification - consequentialism - legal certainty 


\section{Introdução}

A insegurança jurídica sempre foi combatida pela legislação brasileira. Diversos são os princípios, as regras e os dispositivos, constitucionais ou legais, que dispõem sobre a segurança jurídica. A constatação da sua efetividade na realidade jurídica prática vai, entretanto, na direção contrária. Não são poucos os exemplos de instabilidade jurídica que rodeiam os noticiários, os artigos científicos e a comunidade jurídica como um todo.

A despeito da existência de um direcionamento constitucional e legal na busca da segurança jurídica das relações, é possível apontar um grande entrave que se opera sistematicamente, qual seja, o receio dos gestores públicos na tomada de decisão devido à instabilidade jurídica dos entendimentos dos órgãos legitimados que, no futuro, podem gerar a punição deste gestor mediante ações próprias. Quer dizer, os órgãos de tal natureza, como os Tribunais de Contas, os Ministérios Públicos e a Defensoria Pública, arvoram-se em impor entendimentos jurídicos tidos como melhores do que aqueles tomados na origem, desconsiderando a posição do administrador público ante os limites fáticos.

Os órgãos supramencionados não teriam, a priori, condições de substituir a decisão tomada pelo gestor público, até porque essa não é sua função constitucional. Na divisão constitucional de tarefas, as decisões acerca da administração pública cabem ao seu gestor, o qual, por sua vez, demanda participação de tais órgãos não com a finalidade de repressão unicamente, mas também de orientação.

A busca pela segurança jurídica é o grande objetivo da nova Lei de Introdução às Normas do Direito Brasileiro (LINDB), a qual aclarou a forma pela qual os envolvidos, quais sejam, o gestor público, o órgão de controle e, eventualmente, um terceiro particular, devem proceder na tomada de decisões, com respeito à segurança jurídica, à previsibilidade consequencialista e aos limites institucionais de cada um. A objetivação de demandas repetitivas, com inspiração nas técnicas inseridas no ordenamento jurídico pelo Código de Processo Civil de 2015, promete aportar uma nova condição no cotidiano da administração pública: a segurança jurídica esperada e necessária.

Pretende-se neste trabalho adentrar no estudo do conceito atual da garantia de segurança jurídica e os seus reflexos nos atos administrativos, bem como demonstrar a inter-relação deste princípio com a objetivação das demandas inserida no ordenamento jurídico pátrio a partir do novo art. 30 da LINDB. 
Primeiramente iremos tratar dos conceitos de segurança jurídica e consequencialismo, posto que são basilares para a compreensão do nosso estudo, para em sequência adentrar na objetivação pretendida pelo legislador interno ao fazer inserir o art. 30 na LINDB, enfrentando as consequências práticas e jurídicas dessa inovação legislativa.

\section{O conceito de segurança jurídica e o consequencialismo na nova LINDB}

A segurança jurídica é um valor principiológico previsto na Constituição Federal de 1988 e disciplinado nos parágrafos do art. 6o da LINDB. Para Silva, ${ }^{1}$ tal princípio tem duas facetas, uma objetiva e outra subjetiva. Esta está ligada à legítima confiança dos cidadãos ante as condutas estatais. Já aquela se refere aos mandamentos contidos no art. 5ํ, XXXV, da Constituição Federal, ou seja, o respeito ao direito adquirido, ao ato jurídico perfeito e à coisa julgada.

A ideia de segurança jurídica está intrinsecamente relacionada com o estado democrático de direito e com a proteção à legítima confiança que os cidadãos devem ter com relação à atuação do Estado. A segurança jurídica também se revela aplicável no âmbito particular, destacando-se, como exemplo, a própria noção de prescrição contida no Código Civil. Por não ser objeto do presente estudo, não será aprofundada a aplicabilidade das normas jurídicas em âmbito outro que não o público. Assim, todo o sistema jurídico deve se basear no mínimo de previsibilidade jurídica, com o fito de evitar a perpetuação de insegurança nas relações jurídicas encetadas.

O mencionado princípio encontra-se expressamente previsto no caput do art. 5 da Constituição da República, havendo, por todo o seu corpo textual, exemplos, bem como garantias, de sua aplicabilidade; cite-se a impossibilidade de a lei prejudicar o direito adquirido, o ato jurídico perfeito e a coisa julgada. Ressalte-se que não se desconhece o enorme rol de direitos, grande parte de cunho programático, delineados pela Constituição Federal de 1988, sendo que, para a sua concretização, o Constituinte tratou com minúcias das formas possíveis de serem utilizadas pelos gestores públicos.

1 SILVA, Almiro do Couto E. O princípio da segurança jurídica (proteção à confiança) no direito público brasileiro e o direito da administração pública de anular seus próprios atos administrativos: o prazo decadencial do art. 54 da Lei do Processo Administrativo da União (Lei no 9.784/99). Revista da Procuradoria-Geral do Estado do Rio Grande do Sul, Porto Alegre, v. 27 , n. 57, p. 33-75, 2004. 
As alterações feitas na LINDB tiveram como escopo orientar a atuação do administrador público em diálogo com os órgãos decisores, no intuito de aumentar a segurança jurídica na aplicação das normas. Isto é, em razão da hipertrofia do controle, feito por órgãos incumbidos de tal dever, como o controle interno, o externo e o Ministério Público, o legislador entendeu ser necessário promover um ambiente dialógico entre tais órgãos (e entes) e o gestor público, com a finalidade de evitar a infantilização da gestão pública, ou seja, o receio do gestor público de inovar na administração e sofrer punição posterior.

Não que tal obrigação, qual seja, a segurança jurídica, já não tivesse concretude constitucional, na medida em que, no sistema piramidal, no qual no vértice está alocado o bloco de constitucionalidade, quaisquer disposições que infringissem as normas constitucionais são, na sua gênese, inválidas, inclusive o desrespeito ao art. 5ํㅡ, XXXV, da Constituição Federal, o qual sintetiza o princípio da segurança jurídica.

Esse é o entendimento de Britto, ${ }^{2}$ para quem "(...) os valores de berço constitucional são o hierárquico referencial de todos os outros valores de matriz infraconstitucional (...)", concluindo que tais vetores devem ser seguidos sob pena de invalidade dos atos editados à sua revelia.

No plano infraconstitucional, a lei federal de processo administrativo já previa a motivação como princípio a ser seguido pela administração pública, embora tal normativo tenha se revelado insuficiente. Foi nesse contexto de debates que surgiu a necessidade de alteração da LINDB, que, por ser uma norma sobre normas, gozaria de uma maior força interpretativa.

Nos termos do art. 2º, caput, da Lei no 9.784/99, ${ }^{3}$ a administração pública obedecerá, entre outros, ao princípio da motivação. Como bem destacado por Viana, ${ }^{4}$ a " (...) fundamentação se encontra diretamente ligada à indicação dos dispositivos legais, não sendo, portanto, motivação". O que a lei exige é a motivação, ou seja, o debruçar do decisor sobre o miolo fático e normativo do processo examinado e não a indicação de fundamentos jurídicos soltos, isto é, a fundamentação crua.

2 BRITTO, Carlos Ayres. O humanismo como categoria constitucional. Belo Horizonte: Fórum, 2007. p. 88.

3 BRASIL. Lei no 9.784, de 29 de janeiro de 1999. Regula o processo administrativo no âmbito da Administração Pública Federal. 1999.

4 VIANA, Ismar. Fundamentos do processo de controle externo: uma interpretação sistematizada do texto constitucional aplicada à processualização das competências dos tribunais de contas. Rio de Janeiro: Lumen Juris, 2019. p. 187-192. 
No parágrafo único do art. 20 da LINDB, introduzido pela Lei no 13.655/2018, o legislador ordinário ressalta a importância da motivação de tais atos, exigindo que ela demonstre a necessidade e a adequação da medida imposta ou da invalidação de ato, contrato, ajuste, processo ou norma administrativa, inclusive em face das possíveis alternativas (Brasil, 2018), ${ }^{5}$ tratando, pois, acerca do consequencialismo nas decisões administrativas.

O consequencialismo, para Oliveira, ${ }^{6}$ é a tomada de decisão com base nas consequências práticas que dela advém, sendo, nas palavras do próprio autor, um "(...) olhar para o futuro e não para o passado".

É de se destacar que a aferição desse consequencialismo deverá ser concretizada a partir dos dados e informações que integram o próprio processo, o que exige, com efeito, do gestor o dever motivacional ainda mais alargado dos atos administrativos. Como há a conhecida presunção da legitimidade dos atos administrativos, isso acaba por impor, de igual forma, o dever de motivação mais acentuado do agente controlador para afastar essa presunção, que, por sua vez, é relativa, mensurando as consequências práticas do que foi processualmente discutido. Não se trata, pois, de impor ao agente decisor na esfera controladora o dever de antever, em uma abstração futurológica, o alcance da decisão, até porque a ele não é imposto o dever de conhecer a realidade prática do órgão prolator da decisão administrativa.

Pretende-se, sobretudo, operar mudanças no agir institucional dos Tribunais de Contas, órgãos de controle externo da atividade administrativa, impondo-lhes restrições de atuação baseadas em argumentos cegos à realidade administrativa, bem como ampliando o diálogo entre tais entes e os gestores.

A consideração das consequências jurídicas e administrativas fica limitada aos fatos e fundamentos de mérito e jurídicos que são esperados do decisor no exercício diligente de sua atuação, ${ }^{7}$ não se exigindo uma amplitude para além daquela constante na colheita de informações ou constante nos autos do processo que originou a decisão.

5 Brasil. Lei $n^{\underline{o}}$ 13.655, de 25 de abril de 2018. Inclui no Decreto-Lei $n^{-}$4.657, de 4 de setembro de 1942 (Lei de Introdução às Normas do Direito Brasileiro), disposições sobre segurança jurídica e eficiência na criação e na aplicação do direito público.

6 OLIVEIRA, Rafael Carvalho Rezende. A releitura do direito administrativo à luz do pragmatismo jurídico. Revista de Direito Administrativo, Rio de Janeiro, v. 256, p. 129-163, jan./abr. 2011.

7 Brasil, Decreto $n^{-}$9.830, de 10 de junho de 2019. Regulamenta o disposto nos art. 20 ao art. 30 do Decreto-Lei n ${ }^{\circ} 4.657$, de 4 de setembro de 1942, que institui a Lei de Introdução às normas do Direito brasileiro. 
Morais e Zolet, ${ }^{8}$ ao comentarem o art. 20 da LINDB, discorrem que "(...) a nova redação da LINDB avança em espaço controverso da Teoria do Direito contemporânea, qual seja da possibilidade das decisões judiciais se utilizarem de argumentação consequencialista sem decorrer em mero ativismo judicial".

Justen Filho, ${ }^{9}$ acerca do mesmo dispositivo legal, entende que as inovações do art. 20 da LINDB têm como objetivo a redução de práticas estatais geradoras de insegurança jurídica com base na redução da carga subjetiva e superficial das decisões que passam a ter a obrigação de examinar as reais características fáticas dos casos concretos.

Viana, ${ }^{10}$ ao comentar o mencionado artigo, compreende que a finalidade dessa inovação legal foi a de alcançar a segurança jurídica no diálogo entre o gestor e o órgão controlador, “(...) protegendo, de um lado, o agente público responsável pela tomada da decisão, e de outro, o particular que, em razão da decisão tomada, mantém vínculo com a Administração Pública".

Esse diálogo institucional se revela imprescindível para a manutenção da estabilidade nas relações jurídicas mediadas pelos órgãos de controle, em especial para que sejam evitadas surpresas oriundas da ausência de sopesamento entre a factual realidade da administração pública e os princípios abstratos dotados de grande elasticidade interpretativa.

O art. 20 da LINDB tem a intenção de limitar o juízo subjetivo decisório. É consabido que qualquer decisão possui uma carga subjetiva, porém a mens legis foi exigir do decisor a utilização de elementos concretos como subsídio para as decisões. Elimina-se, pois, a possibilidade de decisão com base unicamente em preceitos vagos e sem delimitação jurídica e fática objetiva. Para Justen Filho, ${ }^{11}$ a aplicação da norma jurídica exige atenção ao conteúdo, aos mandamentos e ao processo previstos na norma de hierarquia superior, razão pela qual "isso significa a vedação pela ordem jurídica de solução concreta fundada em avaliações puramente subjetivas da autoridade estatal".

Antevendo as robustas alterações que poderiam ser implementadas e de fato o foram - pelo Projeto de Lei no 349/2015 do Senado Federal, do

8 Morais e Zolet, A nova LINDB e os problemas da argumentação consequencialista, op. cit., p. 510 .

9 JUSTEN FILHO, Marçal. Art. 20 da LINDB: dever de transparência, concretude e proporcionalidade nas decisões públicas. Revista de Direito Administrativo, Edição Especial: Direito Público na Lei de Introdução às Normas de Direito Brasileiro - LINDB (Lei no 13.655/2018), Rio de Janeiro, p. 13-41, nov. 2018. Disponível em: <http://bibliotecadigital.fgv.br/ojs/index.

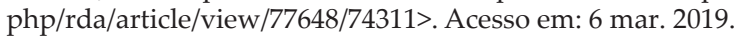

10 Ismar Viana, Fundamentos do processo de controle externo, op. cit., p. 187-192.

11 Marçal Justen Filho, Art. 20 da LINDB, op. cit., p. 15. 
qual se originou a Lei $\mathrm{n}^{\mathrm{0}}$ 13.655/2018, Leal ${ }^{12}$ destaca que a exclusividade principiológica como fundamento das decisões é motor suficiente para que se busque a redução da insegurança jurídica, visto que, para o autor, "sem mecanismos para domesticar essas incertezas, sobra subjetividade. Com isso, o processo decisório nas esferas judicial, controladora e administrativa tornase instável e imprevisível". ${ }^{13}$

Como contraponto, $\mathrm{Leal}^{14}$ entende que, em que pese ser salutar a possível - à época - inovação legislativa, na redação do atual art. 20 da LINDB, que remete aos ditos raciocínios consequencialistas, a ausência de critérios para neutralizar as dificuldades inerentes ao julgador aliada à necessidade de que ele considere as consequências de sua decisão poderia conduzir à ineficácia da Lei, isto é, "o projeto de lei pode não ser capaz de reduzir as incertezas de processos decisórios que se sustentem sobre princípios vagos ou que invalidem os atos referidos no artigo 26 que se pretende incluir na lei de introdução".$^{15}$

Schuartz ${ }^{16}$ destaca que, na pretensão de fundamentação de decisões a partir da análise de suas consequências, o prolator da decisão estará sujeito a questionamentos - prestação de contas, nas palavras do autor - , cuja resposta exige conhecimento de áreas do saber diversas da puramente jurídica, isso "porque qualquer juízo consequencialista contém uma dimensão descritiva, na qual deverá ser positivamente especificada, para cada alternativa de decisão disponível, a sua respectiva consequência $(. . .)^{\prime \prime} \cdot{ }^{17}$ Conclui o autor que a especificação dada será considerada inadequada quando for possível a demonstração de que as consequências da decisão podem ser diversas daquelas pensadas pelo decisor.

Ainda tratando sobre as possíveis falhas na legislação, Leal ${ }^{18}$ afirma haver

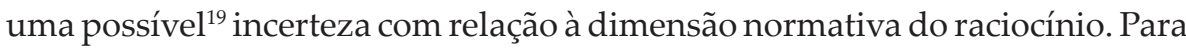

12 LEAL, Fernando. Inclinações pragmáticas no direito administrativo: nova agenda, novos problemas. O caso do PL 349/151. In: ___ MENDONÇA, José Vicente Santos de. Transformações do direito administrativo: consequencialismo e estratégias regulatórias. Rio de Janeiro: FGV, 2016.

3 Ibid., p. 25.

4 Ibid., p. 25.

Ibid., p. 28.

16 SCHUARTZ, Luis Fernando. Consequencialismo jurídico, racionalidade decisória e malandragem. Revista de Direito Administrativo. Rio de Janeiro, v. 248, p. 130-158, 2008.

17 Ibid., p. 131.

18 Leal, Inclinações pragmáticas no direito administrativo, op. cit.

19 O autor destaca que a tomada de decisão jurídica envolve dois tipos de incertezas, estando o primeiro localizado na dimensão positiva ou descritiva do raciocínio e o segundo dizendo respeito à dimensão normativa do raciocínio. 
a tomada de uma escolha, o agente público deve antever as consequências práticas da sua decisão e indicar qual o critério utilizado para justificar as escolhas efetuadas. Entretanto, para o autor, "no caso do artigo 20, não está claro se esse critério de valoração é o princípio vago que o decisor pretende adotar ou algum outro, como segurança jurídica, igualdade ou eficiência" ${ }^{20}$ Conclui que, ainda que sejam positivados os critérios na lei, caso sejam vagos (proporcionalidade, interesses gerais), a inovação legislativa poderia retomar os mesmos problemas que pretendia solucionar: a fundamentação com base em critérios abstratos.

O Decreto $n^{-9} 9.830 / 2019,{ }^{21}$ ao regulamentar os dispositivos da LINDB, dispõe, em seu art. $2^{\circ}$, que a decisão será motivada com a contextualização dos fatos, quando cabível, bem como com a indicação dos fundamentos de mérito e jurídicos. $\mathrm{O}$ consequencialismo argumentativo encontra-se ainda mais explícito no $\S 1$ ㅇ do mesmo artigo, na medida em que se determina que a motivação da decisão contenha, além dos seus fundamentos, a apresentação da congruência entre as normas e os fatos que a embasaram, de forma argumentativa, ou seja, a motivação e não a simples fundamentação.

A motivação ${ }^{22}$ do ato administrativo indicará ainda as normas, a interpretação jurídica, a jurisprudência ou a doutrina que a embasaram, de forma a aumentar a segurança jurídica nas decisões. Possibilita-se ainda a motivação per relacionem ou aliunde, a ser constituída por declaração de concordância com o conteúdo de notas técnicas, pareceres, informações, decisões ou propostas que precederam a decisão.

$\mathrm{O}$ art. 3º do Decreto $\mathrm{n}^{\mathrm{o}}$ 9.830/1999, acerca da motivação nas decisões baseadas em valores jurídicos abstratos, aprofunda ainda mais o consequencialismo quando ela se basear exclusivamente em valores jurídicos abstratos, pois o decisor, além do dever de motivação previsto no art. 2 @ do mesmo decreto, deverá observar as consequências práticas da decisão, tudo em conformidade com o art. 20 da LINDB. Valores jurídicos abstratos, para os fins da lei em comento, são aqueles previstos em normas jurídicas com alto grau de indeterminação e abstração, conforme o art. $3^{\circ}$, $\S 1^{\circ}$, do Decreto no $-9.830 / 2019$.

É importante destacar que o decreto exige que o decisor apresente apenas aquelas consequências práticas que, no exercício diligente de sua

20 Leal, Inclinações pragmáticas no direito administrativo, op. cit., p. 28.

21 Brasil, Decreto no 9.830, de 10 de junho de 2019, op. cit.

22 Ibid. 
atuação, ele consiga vislumbrar diante dos fatos e fundamentos de mérito e jurídico, conforme o art. $3^{\circ}$, $\S 2^{\circ}$, do decreto mencionado, devendo a motivação demonstrar a necessidade e a adequação da medida imposta, inclusive consideradas as possíveis alternativas e observados os critérios de adequação, proporcionalidade ${ }^{23}$ e razoabilidade. ${ }^{24}$ Acerca do princípio da proporcionalidade, não custa ressaltar que Ávila entende que esse postulado depende da relação de causalidade entre meio e fim e se aplica sempre que houver uma medida concreta destinada a realizar uma finalidade.

O consequencialismo está presente especialmente quando houver a invalidação de atos, contratos, ajustes, processos ou normas administrativas, conforme previsão legislativa expressa no art. 21 da LINDB. O art. $4^{\circ}$ do Decreto no 9.830/2019 destaca a exigência da fundamentação nos moldes anteriormente tratados, porém, adicionalmente, a decisão deverá indicar, de modo expresso, as suas consequências jurídicas e administrativas. ${ }^{25}$ A motivação, nos termos do $\S 2$ o do art. 4ํ do Decreto no 9.830/2019, demonstrará a necessidade e a adequação da medida imposta, consideradas as possíveis alternativas e observados os critérios de proporcionalidade e de razoabilidade, em consonância com as diretrizes contidas no art. $2^{\circ}$ da Lei de Processo Administrativo Federal. ${ }^{26}$

O próprio parágrafo único do art. 21 da $\operatorname{LINDB}^{27}$ já previa que a decisão deveria indicar as condições para que a regularização ocorra de modo proporcional e equânime e sem prejuízo aos interesses gerais, não se podendo impor aos sujeitos atingidos ônus ou perdas que, em função das peculiaridades do caso, sejam anormais ou excessivos.

O consequencialismo, presente em todo o texto legal e disciplinado pelo decreto sob análise, também é externalizado quando o art. $4^{\circ}$, $\S 4^{\circ}$, do Decreto no 9.830/2019, possibilita que o decisor observe as consequências jurídicas e administrativas da decisão para a administração pública e para o administrado, podendo restringir os efeitos da declaração ou mesmo decidir que sua eficácia se iniciará em momento posteriormente definido, ou seja, aplicar eficácia prospectiva à decisão. ${ }^{28}$

23 ÁVILA, Humberto. Teoria dos princípios: da definição à aplicação dos princípios jurídicos. 18. ed. São Paulo: Malheiros, 2018. p. 207.

24 Brasil, Decreto $n^{-}$9.830, de 10 de junho de 2019, op. cit.

25 Ibid.

26 Brasil, Lei no 9.784, de 29 de janeiro de 1999, op. cit.

27 BRASIL. Decreto-Lei $n^{0}$ 4.657, de 4 de setembro de 1942. Lei de Introdução às normas do Direito Brasileiro. (Redação dada pela Lei nº 12.376, de 2010).

28 BRASIL. Lei n $n^{0}$ 9.868, de 10 de novembro de 1999. Dispõe sobre o processo e julgamento da ação direta de inconstitucionalidade e da ação declaratória de constitucionalidade perante o Supremo Tribunal Federal. 
Incorporando, mutatis mutandis, o procedimento previsto na Lei no 9.868/ 1999, que trata acerca do processo e do julgamento da ação direta de inconstitucionalidade e da ação declaratória de constitucionalidade perante o Supremo Tribunal Federal e permite, no seu art. 27, a modulação dos efeitos da decisão, com vistas a proteger, entre outros valores, a segurança jurídica, o § 3o do art. $4^{\circ}$ do Decreto no 9.830/1999 permite a modulação dos efeitos da decisão administrativa, indicando-se as condições para que a regularização ocorra de forma proporcional e equânime e sem prejuízo aos interesses gerais. A intenção da modulação é a busca pela mitigação dos ônus ou das perdas dos administrados ou da administração pública que sejam anormais ou excessivos em função das peculiaridades do caso.

O decreto trata ainda de decisão que determine a revisão quanto à validade de atos, contratos, ajustes, processos ou normas administrativas cuja produção de efeitos esteja em curso ou tenha sido concluída. A fim de fomentar a segurança jurídica e evitar prejuízos desarrazoados, o decisor deverá levar em consideração as orientações gerais da época quando da prolação da decisão.

Veda-se, ainda, a declaração de invalidade de situação plenamente constituída devido à mudança posterior de orientação geral, dando-se concretude ao princípio do ato jurídico perfeito, um dos fundamentos constitucionais da segurança jurídica, previsto no art. 5o, XXXV, da Constituição Federal e regulamentado pelo art. $6^{\circ}$, $\S 1$, da LINDB, com redação dada pela Lei no 3.238/1957, ${ }^{29}$ que considera ato jurídico perfeito o já consumado segundo a lei vigente ao tempo em que se efetuou. A orientação geral referida é considerada pelo Decreto no $9.830 / 2019^{30}$ como as interpretações e as especificações contidas em atos públicos de caráter geral ou em jurisprudência judicial ou administrativa majoritária e as adotadas por prática administrativa reiterada e de amplo conhecimento público.

É importante consignar que o $\S 2$ 을 do art. 5o do Decreto no 9.830/2019 não exclui a possibilidade de suspensão de efeitos futuros de relação em curso, fator relevante para se evitar eventuais consequências danosas à administração pública e aos administrados, estando em consonância com o art. 24 da nova LINDB, o qual veda a declaração de invalidade de situações

29 BRASIL. Lei noำ 3.238, de 1ํo de agosto de 1957. Altera disposições da Lei de Introdução ao Código Civil.

30 Brasil, Decreto n⿳⺈ 9.830, de 10 de junho de 2019, op. cit. 
plenamente constituídas com base em mudança posterior de orientação geral, privilegiando-se a segurança jurídica pela administração pública.

O legislador se preocupou com a discricionariedade das decisões baseadas em normas de conteúdo indeterminado. Assim, a decisão administrativa que estabelecer interpretação ou orientação nova sobre norma de conteúdo indeterminado, considerando-se nova interpretação ou nova orientação aquela que altera o entendimento anterior consolidado, e impuser novo dever ou novo condicionamento de direito, preverá regime de transição, quando indispensável para que o novo dever ou o novo condicionamento de direito seja cumprido de modo proporcional, equânime e eficiente e sem prejuízo aos interesses gerais. ${ }^{31}$

Em resposta aos comentários tecidos pela Consultoria Jurídica do TCU ao PL nº 7.448/2017, destaca-se que se “veda, assim, motivações decisórias vazias, apenas retóricas ou principiológicas, sem análise prévia de fatos e de impactos". 32

O encargo interpretativo é direcionado sobretudo ao controlador dos atos dos gestores públicos, na medida em que a LINDB exige a consideração dos obstáculos e das dificuldades reais do gestor, bem como das exigências das políticas públicas a seu cargo, sem prejuízo dos direitos dos administrados, quando da interpretação das normas sobre gestão pública. Pretende-se que os órgãos controladores entrem em diálogo institucional com o gestor público, de forma que este reste amparado, juridicamente, pelas orientações daqueles. $\mathrm{O}$ alcance da materialidade dessa comunicação pode se dar por meio da objetivação de demandas administrativas, com a edição de súmulas e orientações vinculantes que, em última instância, darão efetividade ao princípio da segurança jurídica.

Dá-se, também, tangibilidade ao princípio constitucional implícito da proporcionalidade, na medida em que aquele que julga está legalmente obrigado a analisar, detida e motivadamente, os fatos postos no processo concreto, pois não se decidirá com base em preceitos e valores jurídicos abstratos de forma dissociada das consequências práticas possivelmente oriundas do veredito.

31 Ibid.

32 OLIVEIRA, Odilon Cavallari de. Processo TCU/Conjur: TC-012.028/2018-5. Parecer do Projeto de Lei $\mathrm{n}^{\mathrm{o}} 7.448 / 2017$, em face do parecer-resposta elaborado pelos autores do projeto em relação à análise preliminar que esta Consultoria havia realizado. 2018. p. 4. 
No mais, o dispositivo a ser inserido na LINDB é clara aplicação do conhecido princípio da proporcionalidade, que exige do tomador de decisão a comprovação de que a medida a ser adotada é adequada, necessária e proporcional em sentido estrito, porém, por não ser o alvo central do presente estudo, não serão tecidos comentários mais profundos. Entretanto, é imperioso destacar que o $\mathrm{TCU}^{33}$ entende que, sempre que o poder público tiver de decidir tendo por base um conflito de bens jurídicos de qualquer espécie, deve-se sempre averiguar se é possível que a referida medida leve à realização pretendida (adequação), se esta será a menos restritiva possível aos direitos e interesses envolvidos (critério da necessidade) e, por fim, analisar se a finalidade pública buscada será valorosa a ponto de justificar a restrição imposta (critério da proporcionalidade em sentido estrito).

Esse entendimento é compartilhado por Mello, ${ }^{34}$ que entende que, se há margem de discricionariedade, possibilitando-se a coexistência de dúplice entendimento, ou seja, soluções em um sentido para determinado conjunto de casos e em outro sentido para outra espécie de casos, é porque se pretende que a solução mais justa, adequada e pertinente aos casos seja feita com base na situação concreta e na finalidade do complexo normativo aplicável ao caso.

A busca pela melhor solução ao caso concreto estaria intrinsecamente ligada a seu resultado prático na esfera social, partindo-se, entretanto, dos valores normativos postos pelo ordenamento jurídico. Esse contexto é revelado no estudo do pragmatismo jurídico, que pondera sobre a necessidade de se averiguar a real utilidade prática de determinada decisão, ou seja, o seu impacto na ordem social, sem que se despreze o conjunto normativo aplicável. A ideia de pragmatismo surge da corrente científico-filosófica datada do final do século XIX, em virtude da necessidade de se atribuir utilidade prática ao objeto em estudo jurídico, após a incidência de todos os possíveis desdobramentos no plano da realidade.

Nesse sentido, o pragmatismo jurídico, ao averiguar com antecedência as possíveis consequências reais das decisões tomadas, deve ter por base também o conceito de juridicidade, hoje muito aplicado pelos Tribunais Superiores.

33 MARQUES NETO, Floriano de Azevedo et al. Resposta aos comentários tecidos pela Consultoria Jurídica do TCU ao PL no 7.448/2017. s.d. p. 4-5. Disponível em: <www.sbdp.org.br/wp/wpcontent/uploads/2018/04/Parecer-apoio-ao-PL-7.448-17.pdf>. Acesso em: 3 mar. 2020.

34 MELLO, Celso Antônio Bandeira de. Discricionariedade e controle jurisdicional. São Paulo: Malheiros, 2017. 
Em que pese a inexistência de conceito hermético, o pragmatismo jurídico congrega as necessidades de eficiência e praticidade às decisões jurídicas, em todas as esferas decisórias.

Kaufmann, ${ }^{35}$ em monografia sobre o tema, destaca que "o pragmatismo jurídico não é propriamente um conceito a ser identificado e esclarecido, mas uma postura interpretativa do processo de decisão, da historicidade e pessoalidade dessa mesma hermenêutica, da limitação da racionalidade e teorização jurídica e dos próprios objetivos de utilidade e eficiência do direito em relação aos casos concretos. Assim sendo, tudo que for crítica do discurso de elogio da ciência do direito ou das possibilidades racionais, teóricas e abstratas do pensamento jurídico, traz em si um sentido fortemente pragmatista, mesmo que, para isso, não haja leitura do pensamento pragmatista ou conhecimento de seus mais ilustres autores".

Pondere-se que a objetivação das demandas administrativas, a ser analisada em tópico específico, promete impor uma unidade de entendimento vinculante ao órgão de controle, ao gestor e ao particular eventualmente envolvido, sempre com a observância das opções legalmente postas e das consequências práticas da decisão que será tomada.

\subsection{Compatibilidade das decisões com o ordenamento jurídico}

Em nome do próprio princípio democrático, as decisões jurídicas devem ser atreladas ao princípio da legalidade, focando-se, no entanto, nas suas consequências práticas, úteis e socialmente relevantes. É que a conformação das escolhas não prescinde da exigência constitucional de compatibilidade com o ordenamento jurídico. Tal compatibilidade, denominada de juridicidade, está intrinsecamente ligada ao respeito ao complexo normativo em que são englobados todos os aspectos normativos do ato, diferenciando-se, pois, do princípio da legalidade, em uma análise estrita.

Para Oliveira," "a juridicidade é conceito que amplia a tradicional noção de legalidade, entendida esta como a conformidade às regras jurídicas

35 KAUFMANN, Rodrigo de Oliveira. Direitos humanos, direito constitucional e neopragmatismo. Tese (doutorado em direito, estado e constituição) - Universidade de Brasília, Brasília, 2010. p. 98-99).

36 OLIVEIRA, Luciano Henrique da Silva. Análise de Juridicidade de Proposições Legislativas. Núcleo de Estudos e Pesquisas/CONLEG/Senado: Texto para Discussão no 151. Brasília: s.n., 2014. p. 9. 
positivas". Englobando o conceito tradicional de legalidade, o conceito de juridicidade ultrapassa a mera necessidade de embasamento legal para a prática do ato, sendo imprescindível a compatibilidade com as demais normas jurídicas, inclusive com os princípios norteadores do ramo jurídico público.

Na opinião de Meirelles, "a legalidade, como princípio de administração (CF, art. 37, caput), significa que o administrador público está, em toda a sua atividade funcional, sujeito aos mandamentos da lei e às exigências do bem comum, e deles não se pode afastar ou desviar, sob pena de praticar ato inválido e expor-se a responsabilidade disciplinar, civil e criminal, conforme o caso". 37

Não é demais lembrar que, com o pós-positivismo, os princípios foram alçados à condição de normas jurídicas, recebendo do intérprete densificação normativa capaz de fundamentar a antijuridicidade de um ato, possibilitando a anulação dele por afronta ao próprio ordenamento jurídico, ainda que compatível, formalmente, com a lei em vigor. Na aplicação da norma, os princípios insculpidos na cabeça do art. 37 da Constituição Federal devem servir como parâmetro atual para se aferir a própria constitucionalidade dos atos administrativos.

Por denotarem aspectos, por vezes, mais genéricos e abstratos que as regras jurídicas, exigindo-se uma atividade interpretativa de ponderação, tais princípios merecem especial destaque do gestor público, bem como do julgador no caso concreto, tendo em vista a fluidez conceitual histórico-temporal de conceitos jurídicos, como moralidade, impessoalidade, publicidade, eficiência, proporcionalidade e razoabilidade.

O que se impõe, na atualidade, é a consideração da aplicabilidade prática dos postulados normativos na sociedade, além da observância das normas jurídicas referentes ao ramo jurídico em que é inserido o ato. Isso quer dizer que de pouco adianta a existência de disciplina legal específica, rebuscada e bem fundamentada, se, no plano prático, o gestor público se vê impedido de resolver imbróglios concretos por medo de reprimendas oriundas de decisões baseadas em conceitos jurídicos vagos, em especial advindos do órgão de controle.

A efetividade fática mostra-se, por vezes, em dissonância com as diretrizes normativas, na medida em que as necessidades práticas nem sempre

37 MEIRELLES, Hely Lopes. Direito administrativo brasileiro. 42. ed. São Paulo: Malheiros, 2016. p. 93. 
formam paralelo com o que fora estabelecido pelo legislador. Foi a necessidade de se ajustar o plano normativo à realidade, destacando-se as implicações prospectivas de cada decisão e em todas as esferas: decisória, controladora, judicial etc., que impulsionou o legislador a buscar mais segurança jurídica na aplicação da norma. A concatenação sistemática entre ambos os planos é, portanto, uma imposição do que se espera. Para assegurar ainda mais o princípio da segurança jurídica, o art. 30 da LINDB positivou a objetivação de demandas administrativas, cuja intenção é evitar decisões díspares para casos similares.

\section{Objetivação de demandas administrativas como concretizadora da segurança jurídica: a inovação do art. 30 da LINDB}

Estabelecidos os conceitos que servem de alicerce para esse estudo da segurança jurídica no âmbito das relações administrativas, mister aprofundar a análise para adentrar-se ao cerne da questão estudada, ou seja, de que maneira a inovação legislativa trazida pelo art. 30 da nova LINDB traduz o anseio pela concretização da própria segurança jurídica na seara pública por meio da objetivação das demandas administrativas.

É sabido que a segurança jurídica, em todas as suas dimensões, é uma das finalidades do estado democrático de direito e se baseia, em maior ou menor grau, nos princípios da legalidade, da proporcionalidade e da razoabilidade. Ainda quando denominada Lei de Introdução ao Código Civil (LICC), o legislador já se preocupava com os efeitos das decisões, ao sedimentar, no art. 5o do Decreto-Lei no 4.657/1942, que, "na aplicação da lei, o juiz atenderá aos fins sociais a que ela se dirige e às exigências do bem comum". ${ }^{38}$

Fazendo uma breve digressão histórica acerca da objetivação das demandas administrativas ora sob análise, pode-se notar que era pacífico que a antiga LICC era uma lei sobre lei, ou seja, aplicava-se ao conjunto legislativo em vigor, pois versava acerca do modus operandi das normas em geral. O legislador, a fim de evitar eventuais discussões inócuas, achou conveniente alterar a denominação do normativo para reafirmar a sua aplicação a todas as

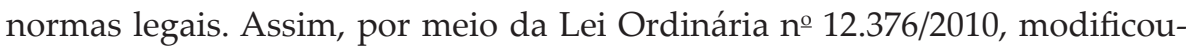
-se a ementa da Lei de Introdução do Código Civil Brasileiro para "Lei de

38 Brasil, Decreto-Lei $n^{\circ} 4.657$, de 4 de setembro de 1942, op. cit., s.p. 
Introdução às Normas do Direito Brasileiro". A própria justificativa do Projeto de Lei nº 6.303/2005, posteriormente convertido na Lei no 12.376/2010, já consagrava que era "reconhecido pela doutrina e pela jurisprudência que a Lei de Introdução ao Código Civil possui âmbito de aplicação mais amplo do que o mencionado em sua ementa $(. . .)^{\prime \prime} .^{39}$

Seguindo ainda o caminho histórico de formação da objetivação administrativa, conclui-se que não é, pois, desconhecida a intenção do legislador de imprimir o aperfeiçoamento das práticas jurídicas, administrativas e controladoras com o intuito de conferir segurança jurídica às relações, fato esse que levou, recentemente, após longas discussões no Congresso Nacional, à edição do normativo $n^{-}$13.655, de 25 de abril de 2018, ${ }^{40}$ acrescentando diversos dispositivos à lei sobre leis anteriormente apontadas. Em apertada síntese, o intuito das "inovações" foi exigir a ponderação entre o plano fático e o normativo do aplicador da norma, em especial quando da aplicação de penalidades ou anulação de situações consolidadas, bem como garantir o aumento da segurança jurídica na aplicação da norma.

Essa também é a posição de Câmara," ${ }^{11}$ para quem “a LINDB não é marcada por apresentar conteúdo revolucionário. Essa observação é cabível desde sua redação original. Não se trata de uma legislação de ruptura, por assim dizer". O mencionado autor, ao se referir a institutos que já estavam presentes no ordenamento jurídico, como o ato jurídico perfeito, a coisa julgada e a irretroatividade da lei, acrescenta, ainda, que "a legislação teve o intento e o mérito de objetivá-las, definindo um padrão exigível de aplicação nas diversas esferas de atuação jurídica".

Fica claro que o art. 30 da nova LINDB, objeto de análise desse estudo, teve prévia gestação na legislação pátria, sendo o produto apresentado pelo legislador brasileiro para responder a essa reivindicação de objetivação das demandas públicas, com o fito de extrair das decisões administrativas a tese abstrata que balizará a atuação da administração pública até ulterior revisão, na mesma linha das inovações feitas na seara processual com o advento do CPC

39 BRASIL. Lei $n^{\circ}$ 12.376, de 30 de dezembro de 2010. Altera a ementa do Decreto-Lei $n^{\circ}$ 4.657, de 4 de setembro de 1942. p. 1.

40 Brasil, Lei $n^{0}$ 13.655, de 25 de abril de 2018, op. cit.

41 CÂMARA, Jacintho Arruda. Art. 24 da LINDB: Irretroatividade de nova orientação geral para anular deliberações administrativas. Revista de Direito Administrativo, Edição Especial: Direito Público na Lei de Introdução às Normas de Direito Brasileiro - LINDB (Lei no ${ }^{13.655 / 2018), ~}$ Rio de Janeiro, edição especial, p. 113-134, nov. 2018. p. 122. 
de 2015. ${ }^{42}$ Explica-se, a segurança jurídica prestigiada foi também a intenção legislativa com a introdução das inovações trazidas no bojo deste Código Processual, que positivou a exigência de uniformização da jurisprudência dos Tribunais, e isso com o intuito de mantê-la estável, íntegra e coerente, ou seja, previsível. No mesmo sentido, a alteração da LINDB trouxe esse objetivo.

\subsection{0 artigo 30 da LINDB e sua operacionalização}

O modus operandi a ser seguido para o incremento da segurança jurídica pode ser encontrado no multimencionado art. 30 da LINDB, uma vez que, já no próprio caput do referido artigo, o legislador autorizou o uso de regulamentos, súmulas administrativas e respostas a consultas pelas autoridades públicas cujos conteúdos terão efeitos vinculantes para os destinatários. Tal prática já é deveras conhecida no seio do processo civil, cujo código em vigor traz, de forma expressa, a sua aplicação supletiva e subsidiária aos processos administrativos. ${ }^{43}$

Adentrando na análise específica da art. 30 da LINDB, pode-se notar que este é direcionado ao aplicador do direito na prática, ou seja, a autoridade ou o agente público, e tem o objetivo principal de aumentar a segurança jurídica na aplicação das normas, criando, nas palavras de Moreira e Pereira, ${ }^{44}$ um "dever de estabilização e uniformidade na criação do Direito", tal qual aquele direcionado aos órgãos jurisdicionais, conforme previsão no art. 926 do Código Procedimental de 2015. ${ }^{45}$

Cumpre ressaltar, no entanto, que tais inovações legislativas não passam indenes de críticas pela literatura especializada. $\mathrm{Na}$ opinião de Souza, ${ }^{46}$ ressaltando a incapacidade de os poderes legislativos e executivo executarem as políticas sociais encartadas na Constituição Federal de 1988, “(...) os dispositivos acima mencionados nada mais são que uma resposta

42 Brasil, Lei nº 13.105, de 16 de março de 2015.

43 Art. 15 do Código de Processo Civil: "Na ausência de normas que regulem processos eleitorais, trabalhistas ou administrativos, as disposições deste Código lhes serão aplicadas supletiva e subsidiariamente" (Brasil, Lei nº 13.105, de 16 de março de 2015, op. cit., s.p.).

44 Moreira e Pereira, Art. 30 da LINDB, op. cit., p. 246.

45 Brasil, Lei $n^{-}$13.105, de 16 de março de 2015, op. cit.

46 SOUZA, Luis Sérgio Fernandes de. As recentes alterações da LINDB e suas implicações. Revista da Escola Superior do Ministério Público de São Paulo, a. 7, v. 14, p. 125-126, jul./dez. 2018. Disponível em: <www.esmp.sp.gov.br/revista_esmp/index.php/RJESMPSP/article/ view/366/340340384>. Acesso em: 9 jun. 2020. 
do legislador às tendências de judicialização da política e da politização do Judiciário (...)". Prossegue pontuando o citado autor que “(...) o legislador, nas recentes alterações promovidas, buscou uma interpretação consequencialista, na linha do utilitarismo de MacCormick (...)". Assim, tecendo comentários críticos, conclui acerca da questão ética, sob uma análise crítica, que esta se revela “(...) apenas como pretexto para o estabelecimento de uma estratégia de poder, pois o legislador, com a desculpa de garantir valores positivos (segurança, eficiência, interesse geral, etc.), buscou desarmar o ativismo judicial, inclusive".

Há, pois, corrente que enxerga um viés utilitarista por parte da modificação legislativa na LINDB, em especial no art. 30 aqui analisado, como um backlash do Poder Legislativo em resposta ao ativismo judicial. A despeito dessa linha de pensamento, é importante ressaltar que a segurança jurídica é valor defendido na própria Constituição Federal, não sendo, portanto, inovação recente a busca pela sua concretização.

Acerca da instrumentalização do aparato estatal capaz de assegurar o aumento da segurança jurídica, é importante destacar que esta é feita pela própria lei, que autoriza - impõe, na realidade - o dever de concretização das decisões jurídicas por meio de regulamentos, súmulas administrativas e respostas a consultas. A intenção do legislador é clara: fomentar o uso de mecanismos acessíveis aos administrados - e à própria administração pública - que permitam o conhecimento do entendimento administrativo sobre determinada matéria. Consagra-se, portanto, a objetivação das demandas administrativas, na medida em que de um precedente, ou de um conjunto de decisões reiteradas, se extrai a norma jurídica a ser aplicada em casos análogos, garantindo, com efeito, a segurança jurídica das partes que participaram da decisão.

Seguindo esse caminho de concretização da segurança jurídica, percebe-se que a legitimação das escolhas públicas tem sido tema de grande importância nas legislações atuais, de forma que, paulatinamente, tem se abandonado a feição unilateral da administração pública (administração pública monológica) e se adotado uma conduta mais aberta à colheita de posições opinativas da sociedade civil (administração pública dialógica). Nessa esteira, o art. 18 do Decreto no 9.830/2019 abre a possibilidade para que a autoridade pública realize consulta pública para manifestação de interessados, devendo tal consulta ser realizada preferencialmente por meio eletrônico, a fim de possibilitar a participação dos possíveis afetados na criação - edição - de atos normativos. 
Essa conduta está em consonância com os ditames da Constituição Federal de $1988,{ }^{47}$ que, na parte voltada à administração pública, já no caput do seu art. 37, traz a publicidade, consectária da segurança pública, como princípio regente de toda a atividade administrativa. Consigne-se que a participação popular nos atos normativos da administração pública, pelo menos na esfera federal, já havia sido regulamentada pela Lei no 9.784/1999, que regula o processo administrativo no âmbito da administração pública federal, ${ }^{48}$ sendo essa participação ativa um dos embriões para o desenvolvimento dos conceitos atuais de objetivação das demandas administrativas.

Ainda sobre esse tema da concretização da segurança jurídica por meio da participação popular, cumpre notar que, nos termos do art. 31 da Lei no 9.78419/99, quando a matéria do processo envolver assunto de interesse geral, o órgão competente poderá, mediante despacho motivado, abrir período de consulta pública para manifestação de terceiros, observadas as condicionantes previstas no próprio normativo mencionado. A fim de garantir a publicidade, o $\S 1^{\text {o }}$ da mesma lei ${ }^{49}$ determina que a abertura da consulta pública será objeto de divulgação pelos meios oficiais, e os resultados da consulta e da audiência públicas, bem como de outros meios de participação de administrados, deverão ser apresentados, indicando-se, ainda, qual o procedimento adotado, na forma do art. 34 da Lei no 9.784/1999.

No Decreto no 9.830/1999, o § 2 o do art. 18 dispõe que a convocação de consulta pública deverá conter a minuta do ato normativo, a sua motivação, bem como a fixação de condições para a participação popular, incluindo-se o prazo para manifestação. $\mathrm{O} \S 3$, , por sua vez, desobriga a autoridade decisora de comentar ou de considerar individualmente as manifestações apresentadas, podendo agrupar manifestações por conexão, como também eliminar aquelas repetitivas ou de conteúdo não conexo com ou irrelevante para a matéria em apreciação.

47 BRASIL. Constituição da República Federativa do Brasil de 1988. 1988.

48 Brasil, Lei no 9.784, de 29 de janeiro de 1999, op. cit.

49 Ibid. 


\subsection{Os institutos da stare decisis e da ratio decidendi no art. 30 da LINDB: instrumentos da objetivação de demandas administrativas}

Para dar concretude ao princípio da segurança jurídica na aplicação das normas previsto expressamente no art. 30 da LINDB, introduzido pela Lei de Segurança Jurídica, ${ }^{50}$ o art. 19 do Decreto no 9.830/1999 impõe que as autoridades públicas atuem com vistas a aumentar a segurança jurídica na aplicação das normas e explicita os instrumentos a serem utilizados para tanto: normas complementares, orientações normativas, súmulas, enunciados e respostas a consultas.

Com relação especificamente ao âmbito consultivo da Advocacia-Geral da União, instituição que, na forma do art. 131 da Constituição Federal de 1988, tem incumbência de atuar como órgão exclusivo na consultoria e no assessoramento jurídico do Poder Executivo, o Decreto no 9.830/2019, em harmonia com a Lei Complementar no 73/1993, ${ }^{51}$ trouxe os arts. 20 e 21 vinculando os órgãos da administração pública federal quando da aprovação dos pareceres pelo presidente da República ou pelos seus auxiliares diretos.

Com base nesse art. 30 da LINDB, as autoridades públicas devem atuar para aumentar a segurança jurídica na aplicação das normas, inclusive por meio de regulamentos, súmulas administrativas e respostas a consultas. Trata-se de um rol meramente exemplificativo dos instrumentos a serem utilizados pela administração pública na consecução dos fins legais de estabilização social. Diversas outras ferramentas podem e devem ser utilizadas para o alcance dessa finalidade, como, à guisa de exemplificação, enunciados administrativos, instruções, manuais de procedimento, e terão caráter vinculante em relação ao órgão ou à entidade a que se destinam, até ulterior revisão.

No âmbito federal, portanto, poderão ser editadas normas complementares, orientações normativas, súmulas, enunciados e respostas a consultas, cujo teor é vinculado aos órgãos ou às entidades da administração pública destinatários, na forma do art. 30, parágrafo único, da LINDB e do art. 19, parágrafo único, do Decreto n 9.830/2019.

50 Brasil, Lei no $n^{0}$ 13.655, de 25 de abril de 2018, op. cit.

51 BRASIL. Lei Complementar n⿳⺈ 73, de 10 de fevereiro de 1993. Institui a Lei Orgânica da Advocacia-Geral da União e dá outras providências. 1991. 
Com relação à competência, a autoridade que representa órgão central de sistema poderá editar orientações normativas ou enunciados que vincularão os órgãos setoriais e seccionais. Da mesma forma, a autoridade máxima de órgão ou da entidade da administração pública poderá editar enunciados que vinculem o próprio órgão ou a entidade e os seus órgãos subordinados. ${ }^{52}$

No intuito de garantir a transparência e a publicidade dos entendimentos administrativos, fator relevante para aumentar a segurança jurídica na aplicação das normas, fim último da lei em comento, o art. 24 do Decreto no 9.830/1999 atribuiu aos órgãos e às entidades da administração pública a obrigação da manutenção atualizada de seus sítios eletrônicos, os quais devem conter as normas complementares, as orientações normativas, as súmulas e os enunciados a que se referem os arts. 19 ao 23 do mesmo normativo.

Cria-se, pois, a imposição de estabilização interna semelhante à ideia de ratio decidendi característica da common law e importada parcialmente pelo Código de Processo Civil, em especial em seu art. 926. Para Streck, ${ }^{53}$ em obra específica sobre o tema, "a ratio decidendi, além de possuir a função de colocar-se como o fundamento jurídico a solucionar os casos no common law, possui a função de evitar arbitrariedade nas decisões judiciais".

A função inibidora de arbitrariedades é de suma importância quando se trata de gestão pública responsável, em especial quando há margem considerável de discricionariedade, de maneira que o gestor pode, legalmente, enquadrar determinada decisão de forma incompatível com o interesse público subjacente à norma de referência.

O controle, seja judicial, popular, administrativo, torna-se deveras difícil em casos análogos, justamente em razão da inexistência de parâmetros objetivos claros de conformação exigíveis. É por isso que a extração da ratio decidendi das decisões administrativas pode auxiliar no controle de desvios de finalidade, ainda mais se for adotada a tese da stare decisis, consagrada pela objetivação das demandas administrativas.

De acordo com a teoria do stare decisis, na seara judicial, os precedentes têm eficácia vinculante. É possível classificar essa vinculação em vertical e em horizontal. A primeira subdivisão diz respeito aos órgãos vinculados de forma hierárquica, enquanto pela segunda é o dever do próprio Tribunal

52 Brasil, Decreto nº 9.830, de 10 de junho de 2019, op. cit.

53 STRECK, Lenio. O precedente judicial e as súmulas vinculantes? Porto Alegre: Livraria do Advogado, 2013. v. 3, p. 45. 
que emanou a decisão respeitá-lo. A ratio decidendi, por sua vez, é a extração da racionalidade da decisão, ou seja, a conclusão extraída pelo julgador ao analisar o caso concreto e aplicar a norma naquele contexto.

Mello ${ }^{54}$ contextualiza o instituto da stare decisis relembrando que tem origem anglo-saxônica e que, em síntese, ocorre quando um caso paradigma, julgado pela Suprema Corte do país, é aplicado a casos análogos. A autora ressalta que a teoria do stare decisis traz a exigência da inalterabilidade, pelas Cortes subordinadas, da questão já decidida pela instância superior.

O Código de Processo Civil de 2015 trouxe esses elementos da doutrina dos precedentes, de origem anglo-saxônica, o que parece ter sido aproveitado pelo legislador ao criar o art. 30 da LINDB. Explica-se. Ao mesmo tempo que o Código adjetivo brasileiro de 2015 inova ressaltando a importância vinculativa dos precedentes judiciais para as decisões proferidas pelos órgãos jurídicos, o art. 30 da LINDB cria uma espécie de precedente administrativo ao impor às autoridades públicas o dever de unificar os entendimentos por meio de "regulamentos, súmulas administrativas e respostas a consultas". Em ambos os casos pode-se notar a explícita intenção de reforçar a segurança jurídica, princípio caro ao estado de direito, conforme já esboçado, podendo notar-se, portanto, uma tendência prática em ambas as searas (judicial e administrativa) pelo prestígio à segurança jurídica.

A objetivação do processo, na realidade, transforma em norma jurídica aquilo que seria apenas uma decisão judicial entre partes, ${ }^{55}$ no bojo das inovações trazidas pelo CPC de 2015, conforme apontado anteriormente, a intenção do legislador é de conferir racionalidade ao sistema judicial e, como fim último, segurança jurídica à sociedade. $\mathrm{O}$ respeito ao precedente administrativo é a intenção legislativa da inovação introduzida pelo art. 30 da LINDB.

Por outro lado, é imperioso notar que a vinculação da administração pública aos precedentes é alvo de críticas por parte da literatura, tendo em vista que esvaziaria a necessária discricionariedade do gestor público. Também as críticas são imprescindíveis para o processo de construção da objetivação de demandas administrativas.

54 MELLO, Patrícia Perrone Campos. Precedentes e vinculação: Instrumentos do stare decisis e prática constitucional brasileira. Revista de Direito Administrativo, Rio de Janeiro, 2005.

55 CARDOSO, Henrique Ribeiro. O paradoxo da judicialização das políticas públicas de saúde no Brasil: um ponto cego do direito? Rio de Janeiro: Lumen Juris, 2016. v. 1. 
Tratando acerca dos precedentes no direito administrativo, Correia ${ }^{56}$ destaca que "a autovinculação ao precedente também vai buscar as suas raízes aos princípios da boa-fé (proibição de venire contra factum proprium) e da segurança jurídica ou tutela da confiança". Por outro lado, o autor destaca também a existência da discricionariedade no direito administrativo, que seria um fator relevante a ser considerado ao se adotar a tese da vinculação dos precedentes administrativos.

No mesmo sentido, Palma ${ }^{57}$ disserta que "o parágrafo único do art. 30 explicita a autovinculação da Administração e dos controladores com relação aos atos de orientação que editarem". A autora, porém, divide o tema. Explica que os regulamentos são normas, razão pela qual devem ser seguidas pela administração pública. Por outro lado, destaca que as "(..) súmulas e respostas a consultas públicas geram uma expectativa de comportamento que precisa ser tutelada para garantia da legítima confiança e da segurança jurídica, evitando-se o casuísmo e o arbítrio".

Com relação à discricionariedade, em sendo o espaço atribuído pela lei para a avaliação do gestor público, pode representar, em tese, um argumento contrário à adoção da teoria do stare decisis. É possível, porém, admitir que a decisão tomada em um procedimento tal qual aquele descrito no art. 30 da LINDB supera esse argumento. Isso porque regulamentos, súmulas administrativas e respostas a consultas serão tomados em conjunto com os órgãos envolvidos, criando uma atmosfera propícia ao surgimento de teses abstratas aplicáveis a processos análogos. Destaque-se, como bem citado no artigo legal sob análise, que é sempre possível a reanálise da tese, posteriormente.

A inclusão do microssistema de demandas repetitivas, que incluiu no ordenamento brasileiro, com adaptações, a stare decisis, surgiu com a necessidade de ampliação da segurança jurídica nos tribunais judiciais. Assim, criou-se um sistema fechado, em que aqueles órgãos de cúpula, com

56 CORREIA, Jorge Alves. O valor do precedente no direito administrativo português. 2019. Disponível em: <www.direitodoestado.com.br/colunistas/jorge-alves-correia/o-valor-do-precedenteno-direito-administrativo-portugues\#: :text=O\%20precedente\%20judicial\%20no $\% 20$ common $\% 201$ law $\% 20 \mathrm{e} \% 20$ no $\% 20$ civil $\% 201$ aw\&text=Assim $\% 2$ C $\% 20$ o $\% 20$ precedente $\% 20 \mathrm{fi}$ xado $\% 20$ pelos,significa $\% 20 \%$ C2\%ABmanter $\% 20 \mathrm{a} \% 20$ decis $\%$ C3\%A3o $\%$ C2\%BB $>$. Acesso em: 8 jun. 2020.

57 PALMA, Juliana Bonacorsi de. A proposta de lei da segurança jurídica na gestão e do controle públicos e as pesquisas acadêmicas. SBDP. 2018. p. 20. Disponível em: <www.sbdp.org.br>. Acesso em: 9 jun. 2020. 
atribuições advindas da Constituição Federal, criam precedentes obrigatórios ou vinculantes.

A transposição desse microssistema para a seara administrativa tem a mesma finalidade: a formulação de teses abstratas que devem ser seguidas pela própria administração em casos similares. Na realidade, a objetivação de demandas administrativas é extração de uma tese impessoal e abstrata a ser aplicada a casos concretos com substratos fáticos iguais ou assemelhados àqueles que deram origem à tese, fomentando, pois, a segurança jurídica dentro da máquina administrativa.

A questão primordial, a despeito da inexistência de um conceito fechado quanto ao conteúdo do instituto, é que a decisão emanada de quem tem competência para isso vincula tanto o próprio julgador que a exarou quanto aqueles que participaram, dialogicamente, do processo decisório. Como não há hierarquia técnica, conforme entendimento do Supremo Tribunal Federal na ADI 3.602,58 a vinculação da decisão fundamenta-se na concepção de unidade institucional, muito debatida por parte da literatura em razão do possível choque com a independência funcional dos membros que compõem os órgãos de controle, em especial os de controle externo.

A unidade institucional fortalece a novidade legislativa prevista da LINDB de vinculatividade das decisões, fomentando, em última análise, a própria segurança jurídica pretendida. Quer dizer, as teses jurídicas exaradas decorrem de um procedimento que legitima a própria tomada de decisão do órgão controlador, o qual fica limitado às conclusões alcançadas por meio de um juízo consequencialista, conforme explicado no tópico anterior.

Por exemplo, no âmbito dos Tribunais de Contas cuja atuação é pautada pela observância do princípio da segregação de funções, as respostas às consultas são processos de natureza objetiva, já que não se discute caso concreto. Essa vinculação é, portanto, alcançada a partir da oitiva dos órgãos técnicos e do Ministério Público de Contas, sendo o voto levado pelo conselheiro ou ministro ao colegiado do Ente, cujo posicionamento prolatado revela a posição institucional sobre a matéria discutida.

Resta, pois, clara a intenção do legislador ao alterar a LINDB: estender o microssistema dos precedentes disposto no CPC à esfera administrativa. A introdução do microssistema de respeito aos precedentes, inovação

58 BRASIL. ADI 3.602. Órgão julgador: Tribunal Pleno. Relator(a): min. Joaquim Barbosa. Julgamento: 14/4/2011. Publicação: 7/6/2011. Brasília, 2011. Acesso em: 5 jun. 2020. 
importada da sistemática da common law pelo Código de Processo Civil de 2015, é plenamente aplicável ao processo administrativo, inclusive por meio de normativo expresso contido em seu art. 15.

Parece que a crítica de Leal $^{59}$ no sentido de que o Projeto deveria “(...) criar regras de parada para a consideração de cadeias de consequências, ou argumentos do tipo 'efeito dominó' e prever mecanismos de vinculação para a solução de casos futuros (...)" foi acolhida pelo legislador.

Essa posição é compartilhada por Moreira e Pereira, ${ }^{60}$ que entendem que o art. 30 da LINDB teve como desdobramento a institucionalização do dever de respeito às decisões administrativas, seja no plano vertical, isto é, toda a estrutura vinculada ao órgão pela hierarquia, seja no plano horizontal, abarcando o próprio órgão ou a entidade prolatora da decisão, com respeito à autonomia funcional, mas com observância, também, da unidade institucional.

A aproximação entre os ramos do direito, que compõe um sistema único, diga-se, tem por consequência colocar em evidência a necessidade de se exigir uma uniformização dos entendimentos no âmbito administrativo, sem desprezar as possibilidades de conformação do mérito por critérios de conveniência e oportunidade característicos das decisões discricionárias. Pelo contrário, releva-se a exigência de que todas as decisões estejam permeadas de aspectos de previsibilidade, juridicidade e racionalidade, características essas do sistema de precedentes positivado no ordenamento jurídico pelo Código de Processo Civil de 2015 e aplicável, supletiva e subsidiariamente, aos processos administrativos.

Avançando ainda mais na harmonização dos sistemas - processual e administrativo - , a inovação perpetrada na LINDB abraça a tão esperada autorização legislativa expressa de se utilizar do microssistema de uniformização jurisprudencial também na seara administrativa, a despeito da sua perene existência antes mesmo da alteração legislativa, de forma que a objetivação de demandas administrativas é uma realidade legislativa capaz de fomentar a segurança jurídica por meio da certeza de que as decisões tomadas com base no juízo consequencialista previsto no art. 20 da LINDB serão observadas pelas partes.

\footnotetext{
59 Leal, Inclinações pragmáticas no direito administrativo, op. cit., p. 30.

60 Moreira e Pereira, Art. 30 da LINDB, op. cit., p. 246.
} 


\section{Conclusão}

A despeito das inúmeras modificações legislativas que vêm ocorrendo, não se desconhece a necessidade de se criar uma esfera mínima de segurança jurídica também no âmbito administrativo não só para fins de proteção à confiança legítima, mas também para se assegurar que os postulados normativos não poderão ser aplicados de forma cega e irresponsável.

As inovações da LINDB trataram sobre a exigência de se avaliar as consequências decisórias sem que se decida com base em categorias jurídicas abstratas sem que estas estejam em consonância com os reais efeitos práticos a serem suportados na realidade fática, bem como possibilitam a objetivação de demandas administrativas, com o intuito de se extrair teses jurídicas abstratas acerca do entendimento administrativo, as quais serão aplicadas aos casos semelhantes futuramente. É dizer, impõe-se a racionalidade do sistema por meio da objetivação de demandas repetitivas, ou seja, o respeito aos precedentes e ratio decidendi das decisões vinculantes previstas nos instrumentos do art. 30 da LINDB, de forma semelhante à teoria do stare decisis incluída no Código de Processo Civil de 2015.

As normas e exigências da LINDB, por sua vez, revelam a aplicabilidade do consequencialismo nas decisões administrativas. A legislação impõe, especialmente, a exigência de se aproximar a teoria da prática, ou seja, as consequências jurídicas das decisões tomadas quanto às hipóteses normativas possíveis.

Pressupõe-se que o administrador público tenha a seu lado, quando do julgamento de seus atos, a noção de que a aplicabilidade fática das normas jurídicas não se revela despida de problemas não antevistos pelo legislado, exigindo-se, pois, o sopesamento entre a norma e os fatos. Considera-se, além disso, que a LINDB busca aproximar a utilidade pragmática da norma ante a intangibilidade dos preceitos normativos, de forma a assegurar a pacificação social, estando em busca da tão cara segurança jurídica.

Por fim, a objetivação de demandas administrativas vem a compor o sistema publicista, com isso aumentando a racionalidade e a eficiência na aplicação das normas pelo decisor, com o intuito de aumentar a segurança jurídica nas decisões do poder público a partir da formulação de uma tese jurídica, abstrata e impessoal, extraída de um caso concreto que vincule a administração pública em casos semelhantes. 


\section{Referências}

ÁVILA, Humberto. Teoria dos princípios: da definição à aplicação dos princípios jurídicos. 18. ed. São Paulo: Malheiros, 2018.

BARROSO, Luis Roberto. Temas de direito constitucional. Rio de Janeiro: Renovar, 2001.

BRASIL. ADI 3602. Órgão julgador: Tribunal Pleno. Relator(a): min. Joaquim Barbosa. Julgamento: 14/4/2011. Publicação: 7/6/2011. Brasília, 2011. Acesso em: 5 jun. 2020.

. Constituição da República Federativa do Brasil de 1988. 1988.

. Decreto $n^{0}$ 9.830, de 10 de junho de 2019. Regulamenta o disposto nos art. 20 ao art. 30 do Decreto-Lei no 4.657, de 4 de setembro de 1942, que institui a Lei de Introdução às normas do Direito brasileiro. 2019.

. Decreto-Lei ñ 4.657, de 4 de setembro de 1942. Lei de Introdução às normas do Direito Brasileiro. (Redação dada pela Lei no 12.376, de 2010). 1942.

. Lei Complementar nº 73, de 10 de fevereiro de 1993. Institui a Lei Orgânica da Advocacia-Geral da União e dá outras providências. 1991.

. Lei no 12.376 , de 30 de dezembro de 2010. Altera a ementa do Decreto-Lei no 4.657, de 4 de setembro de 1942. 2010.

. Lei no 13.105, de 16 de março de 2015. Código de Processo Civil. 2015.

. Lei $n^{-}$13.655, de 25 de abril de 2018. Inclui no Decreto-Lei no 4.657, de 4 de setembro de 1942 (Lei de Introdução às Normas do Direito Brasileiro), disposições sobre segurança jurídica e eficiência na criação e na aplicação do direito público. 2018.

. Lei $n^{o}$ 3.238, de 1o de agosto de 1957. Altera disposições da Lei de Introdução ao Código Civil. 1957.

. Lei no 5.172, de 25 de outubro de 1966. Dispõe sobre o Sistema Tributário Nacional e institui normas gerais de direito tributário aplicáveis à União, Estados e Municípios. 1966.

. Lei no 9.784, de 29 de janeiro de 1999. Regula o processo administrativo no âmbito da Administração Pública Federal. 1999. 
. Lei $n^{2}$ 9.868, de 10 de novembro de 1999. Dispõe sobre o processo e julgamento da ação direta de inconstitucionalidade e da ação declaratória de constitucionalidade perante o Supremo Tribunal Federal. 1999.

BRITTO, Carlos Ayres. O humanismo como categoria constitucional. Belo Horizonte: Fórum, 2007.

CÂMARA, Jacintho Arruda. Art. 24 da LINDB: irretroatividade de nova orientação geral para anular deliberações administrativas. Revista de Direito Administrativo, Edição Especial: Direito Público na Lei de Introdução às Normas de Direito Brasileiro - LINDB (Lei no 13.655/2018), Rio de Janeiro, edição especial, p. 113-134, nov. 2018.

CARDOSO, Henrique Ribeiro. O paradoxo da judicialização das políticas públicas de saúde no Brasil: um ponto cego do direito? Rio de Janeiro: Lumen Juris, 2016. v. 1.

CORREIA, Jorge Alves. O valor do precedente no direito administrativo português. 2019. Disponível em: <www.direitodoestado.com.br/colunistas/jorge-alvescorreia/o-valor-do-precedente-no-direito-administrativo-portugues\#: :text= O \%20precedente $\% 20$ judicial $\% 20$ no $\% 20$ common $\% 201$ aw $\% 20$ e $\% 20$ no $\%$ 20civil $\% 201$ aw \&text $=$ Assim $\% 2$ C $\% 20$ o $\% 20$ precedente $\% 20$ fixado $\% 20$ pelos,significa $\% 20 \% \mathrm{C} 2 \% \mathrm{ABmanter} \% 20 \mathrm{a} \% 20$ decis $\% \mathrm{C} 3 \% \mathrm{~A} 3 \mathrm{o} \% \mathrm{C} 2 \% \mathrm{BB}>$. Acesso em: 8 jun. 2020.

DANTAS, Ivo. Da defesa do Estado e das instituições democráticas na Nova Constituição. Rio de Janeiro: AIDE Editora e Comércio de Livros LTDA, 1989.

DINAMARCO, Cândido Rangel; LOPES, Bruno Vasconcelos Carrilho. Teoria geral do novo processo civil. 3. ed. São Paulo: Malheiros, 2018.

FILHO, Marçal Justen. Art. 20 da LINDB: dever de transparência, concretude e proporcionalidade nas decisões públicas. Revista de Direito Administrativo, Edição Especial: Direito Público na Lei de Introdução às Normas de Direito Brasileiro - LINDB (Lei noo 13.655/2018), Rio de Janeiro, p. 13-41, nov. 2018. Disponível em: <http://bibliotecadigital.fgv.br/ojs/index.php/rda/article/ view/77648/74311>. Acesso em: 6 jun. 2020.

KAUFMANN, Rodrigo de Oliveira. Direitos humanos, direito constitucional e neopragmatismo. Tese (doutorado em direito, estado e constituição) - Universidade de Brasília, Brasília, 2010. 
LEAL, Fernando. Inclinações pragmáticas no direito administrativo: nova agenda, novos problemas. O caso do PL 349/151. In: ; MENDONÇA, José Vicente Santos de. Transformações do direito administrativo: consequencialismo e estratégias regulatórias. 2016.

MARQUES NETO, Floriano de Azevedo et al. Resposta aos comentários tecidos pela Consultoria Jurídica do TCU ao PL no 7.448/2017. s.d. Disponível em: <www. sbdp.org.br/wp/wp-content/uploads/2018/04/Parecer-apoio-ao-PL-7.448-17. pdf>. Acesso em: 3 mar. 2020.

MEIRELLES, Hely Lopes. Direito administrativo brasileiro. 42. ed. São Paulo: Malheiros, 2016.

MELLO, Celso Antônio Bandeira de. Discricionariedade e controle jurisdicional. São Paulo: Malheiros, 2017.

MELLO, Patrícia Perrone Campos. Precedentes e vinculação: instrumentos do stare decisis e prática constitucional brasileira. Revista de Direito Administrativo, Rio de Janeiro, 2005.

MORAIS, Fausto Santos de; ZOLET, Lucas. A nova LINDB e os problemas da argumentação consequencialista. Revista Jurídica - Unicuritiba, v. 4, p. 497$523,2018$.

MOREIRA, Egon Bockmann; PEREIRA, Paula Pessoa. Art. 30 da LINDB: o dever público de incrementar a segurança jurídica. Revista de Direito Administrativo, Rio de Janeiro, Edição Especial: Direito Público na Lei de Introdução às Normas de Direito Brasileiro - LINDB (Lei no 13.655/2018), p. 243-274, nov. 2018.

OLIVEIRA, Luciano Henrique da Silva. Análise de juridicidade de proposições legislativas. Núcleo de Estudos e Pesquisas/CONLEG/Senado: Texto para Discussão $n^{\underline{o}}$ 151. Brasília: s.n., 2014. Disponível em: <www.senado.leg.br/ estudos>. Acesso em: 24 jan. 2020.

OLIVEIRA, Odilon Cavallari de. Processo TCU/Conjur: TC-012.028/2018-5. Parecer do Projeto de Lei no 7.448/2017, em face do parecer-resposta elaborado pelos autores do projeto em relação à análise preliminar que esta Consultoria havia realizado. 2018. Disponível em: <https://portal.tcu.gov.br/lumis/portal/ file/fileDownload.jsp?fileId=8A81881F62B15ED20162F95CC94B5BA4\&inli ne=1>. Acesso em: 20 jan. 2020. 
OLIVEIRA, Rafael Carvalho Rezende. A releitura do direito administrativo à luz do pragmatismo jurídico. Revista de Direito Administrativo, Rio de Janeiro, v. 256, p. 129-163, jan./abr. 2011.

PALMA, Juliana Bonacorsi de. A proposta de lei da segurança jurídica na gestão $e$ do controle públicos e as pesquisas acadêmicas. SBDP. 2018. Disponível em: <www.sbdp.org.br>. Acesso em: 9 jun. 2020.

POSNER, Richard Allen. The problematics of moral and legal theory. s.1.: Chicago: Harvard University Press paperback edition, 2002.

SCHUARTZ, Luis Fernando. Consequencialismo jurídico, racionalidade decisória e malandragem. Revista de Direito Administrativo. Rio de Janeiro, v. 248, p. 130-158, 2008.

SILVA, Almiro do Couto e. O princípio da segurança jurídica (proteção à confiança) no direito público brasileiro e o direito da administração pública de anular seus próprios atos administrativos: o prazo decadencial do art. 54 da Lei do Processo Administrativo da União (Lei no 9.784/99). Revista da Procuradoria-Geral do Estado do Rio Grande do Sul, Porto Alegre, v. 27, n. 57, p. 33-75, 2004.

SOUZA, Luis Sérgio Fernandes de. As recentes alterações da LINDB e suas implicações. Revista da Escola Superior do Ministério Público de São Paulo, a. 7, v. 14, jul./dez. 2018. Disponível em: <www.esmp.sp.gov.br/revista_esmp/ index.php/RJESMPSP/article/view/366/340340384>. Acesso em: 9 jun. 2020.

STRECK, Lenio. O precedente judicial e as súmulas vinculantes? Porto Alegre: Livraria do Advogado, 2013. v. 3.

VIANA, Ismar. Fundamentos do processo de controle externo: uma interpretação sistematizada do texto constitucional aplicada à processualização das competências dos tribunais de contas. Rio de Janeiro: Lumen Juris, 2019. 